Bogoliubov's style is abstract and formal: physical relationships, if mentioned at all, are merely sketched. The first, more general, half of the book can be recommended to every student of theoretical physics; the second part is for those who wish to specialize in the theory of metals and their magnetic properties, and they are advised to turn to Herring's book, Magnetism, $1 \mathrm{~V}$ (Academic Press: New York, 1966) for a profound discussion of the relevance of the polar model.

The translation reads smoothly, but I am baffled why a book of 242 pages without a single illustration should be priced at five pounds.

S. Zienau

\section{PARTICLE MODELS}

\section{The Nuclear Independent Particle Model}

The Shell and Optical Models. By A. E. S. Green, T' Sawada and D. S. Saxon. Pp. $\mathrm{x}+363$. (Academic Press: New York and London, November 1968.) $149 s 4 d$.

THIs book describes the evolution and application of the independent particle model, including the shell model for bound states and the optical model for scattering. In each case, the basic techniques of mathematies and quantum mechanies required for the application of the model are developed and then the use of the model for a pheno. menological analysis of experimental data is described. Finally, there is a discussion of the nucleon-nucleon interaction and the theoretical basis of the independent particle model.

The chapters on the optical model provide a useful, though not very stimulating, review of nucloon--nucleus scattering over a wide range of energies and there is a very useful chapter on velocity-dependent and non-local potentials, but the treatment of the scattering of strongly absorbed projectiles is rather inadequate. The discussion of realistic shell model potentials is again useful but surprisingly out of date, and the lack of recent references is disappointing in view of the recent revival of interest in the shape of the nuclear matter distribution and the difference between the proton and neutron distributions.

There is certainly a need for an authoritative survey of the independent particle model, but the task is a demanding one and the present book, unfortunately, falls short of what one might hope for. It is not clear for whom the book is intended because it begins with the solution of the Schrödinger equation for a square well potential and ends with the Bethe-Goldstone equation and one boson exchange potentials. The detailed discussion of some of the formalism and calculational methods and the extensive list of references may be useful to research students, but the price will hardly be attractive to them.

DAPHNE F. JACKSON

\section{ELECTRICAL COMPONENTS}

\section{Microwave Components}

By P. A. Matthews and I. M. Stephenson. (Modern Electrical Studies.) Pp. viii + 196. (Chapman and Hall: London, February 1969.) $60 s$.

For a number of years there has been a need for a book describing the basic principles of modern microwave components. Excellent design charts for waveguide components can be had free, and instrument manufacturers provide comprehensive notes on facets of microwave measuremonts. Expensive texts are available, examining a number of devices in detail, but the available material has tended to be ton complex for a newcomer to the field. Matthews and Stephenson have produced this short volume in order to fill the gap, aiming particularly at the final year student-now graduate market. It is assumed that the reader will have a fair understanding of electromagnetic theory, and the amount of mathematics in the test is kept to a minimum, preference being given to description and explanation. The clarity of the large number of diagrams materially assists comprehension.

Transmission media for guiding waves are considered, including the parallel-plate and the triplate stripline, coaxial cable, and rectangular, ridged and circular waveguide. In order to discuss these topies Maxwell's equations are stated and the usual equations for components of $\mathbf{H}$ and $\mathbf{E}$ are developed. Transmission line theory serves as an introduction to circle diagrams and impedance? matching, and the scattering matrix is used as a basis for 1 . a discussion of devices with up to four ports.

A detailed evaluation of the non-reciprocal propertiess of ferrites is included, on which deseriptions of a number of types of isolator and circulator are based. Darlington is filter theory is also examined in some depth, for use in a section on microwave filters and cavities.

The remainder of the book, more than one hundred pages, consists, for the most part, of brief qualitative descriptions of a wide variety of components. The most, commonly used forms of passive component are mentioned, including fixed, mechanically variable and elec.trically variable types.

Brief descriptions of various measurement techniques occupy a chapter, and include details of standing war\% measurements, reflectometers, power and noise measurement.

There is some difficulty in relating the sections of general analysis to the components described in subsequent pages, and in some places the presentation is awkward, mixer's and PIN diode attenuators cach being described partly in one chapter, partly in another. Undergraduates should, nevertheless, find the text stimulating, introducing them as it does to a large number of present-day derices. The book makes generally easy and enjoyable reading, and is useful to anyone meeting microwave systems for the first time.

D. P. Howson

\section{Correspondence}

\section{African Rift System}

Str,--The manner in which the African Rift System is portrayed on the new International Tectonic Map of Africa (ITMA 1968)* is both worrying and disappointing to students of African geology.

Officially published geological maps and internationally agreed interpretations made by geologists familiar with the ground have either been modified or ignored. The result can only be described as a caricature of rift geology as we know it today.

It is not possible here to mention or to plot all the variations from officially published national or from internationally accepted sources because of space and map scale problems. but the following examples drawn from the African Rift Zone are quoted. (1) Arabia: 65 per cenis. of the faults shown in ITMA 1968 for the Arabian section of the Afro-Arabian Swell enclosed by the sedimentary Palaeozoic boundary differ either in position. length or direction from those faults plotted on the US (teological Survey-ARAMCO map, 1963 edition, scale J : 2,000.000. No. I-270A. (2) Sinai: trends of folds forming part of the Syrian Are system plotted in northern Sinai vary by as much as $30^{\circ}$ from the published directions ${ }^{-3}$. (3) Sucz:

* Feneral coordinator, (: ('houhert, assistant coordinator, A. Faure-Mrure1: nine sheets, published by the Association of African Geological Sinreers ant TNESc(o, Paris, and drawn and printed by the Tustitnt Cieographicule.
Yational. France, 1968. 